\title{
STRATEGIC APPROACHES TO CROSS-CULTURAL AVAILABILITY FORMATION OF TRANSLATORS: THEORY AND PRACTICE
}

\section{Anzhelika Solodka ${ }^{1}$ \\ Tetiana Moroz ${ }^{2}$}

DOI: https://doi.org/10.30525/978-9934-26-069-8-13

\begin{abstract}
Understanding the fact, that modern education has to become international, leads to improving ability of young people to evaluate the effects of other human positions, different cultures. This research deals with one of the most perspective trends - the formation of availability of students to interact cross-culturally. It can be understood as applied scientific and educational activity. The availability to interact crossculturally is defined as a multidimensional construct reflecting individual ability to respond to the differences positively and interact efficiently with the others from a variety of backgrounds. The authors present conceptual approaches (dialogic, contextual, axiological, facilitation and practical) to cross-cultural education of students-translators as methodological tool aimed at providing a fundamental and holistic understanding of personality development in cross-cultural interaction, foundations and mechanisms of its implementation. The availability to interact across cultures is determined by the following components: productive interaction, positive interaction, ability to cultural transformation, multi subjective interaction. The authors stress, that in the process of cross-cultural interaction its participants need to achieve compliance (compatibility) to a new cultural environment. Ability to cultural transformation and adaptation serves the criteria of availability for cross-cultural interaction. It has been determined that a translator («cultural mediator») is not inherent characteristic, but it is acquired in the real world of interaction and in activities in educational process of high school. It was revealed the dependence of personal efficiency in different cultures from
\end{abstract}

${ }^{1}$ Doctor of Science, Professor of Department of German Philology and Translation,

V.O. Sukhomlynskyi Mykolaiv National University, Ukraine

${ }^{2}$ Candidate of Pedagogical Sciences, Associate Professor,

Dean of Philological Faculty,

V.O. Sukhomlynskyi Mykolaiv National University, Ukraine 
the character and forms of interaction of translator that should promote individual development in cross-cultural context. This aim can be reached in the process of education before the contacts with another culture. For this purpose some practical activates were proposed. The method of interactive modeling is aimed at conscious reproduction of various individual and group situations of cross-cultural communication. The method of stimulation is aimed to create artificially a specific situation of intercultural communication and to predict possible options and outcomes, based on different points of view and aspects. With the use of the method of problem situations students are involved into situations, in which intellectual-ethical issues transform into emotional. Effective communication in translation requires more than mastering grammar and vocabulary of a language. It is the process that requires also knowledge of culture. Culture becomes an important part of the language teaching process. Obtaining cross-cultural competence, translators have a key to successful professional activity.

\section{Introduction}

Cross-cultural skills are the primary requisite of any translator that equip the learner to adapt to different cultural contexts. Availability to interact across cultures has become increasingly important and vital due to transformed economic and social relations. Improvement in the quality of higher education in Ukraine ensures sustainable development based on mutual understanding of people from different countries.

Theories and books on the cross-cultural interaction abound. A theoretical investigation of the cross-cultural interaction process leads to understanding the fact that the participants of the cross-cultural interaction should have abilities to provide its effectiveness $[2 ; 6 ; 12 ; 13 ; 16 ; 19]$.

Various conceptions of the personality across cultures have varying degrees of explanatory or descriptive utility. They all try to define someone whose identity extends significantly beyond the individual's own culture. The terminology describing this kind of personality can be different but it assures that the individual's essential identity is inclusive and comes to grips with a multiplicity of realities $[1 ; 11 ; 15 ; 18]$.

Scholars suggest that international students have problems transitioning into overseas academic environments, as their prior learning methods impede absorption of new instructional styles. 
The theories representing cultural intelligence (CQ) stress on individual capability to function effectively across cultures. The cultural intelligence approach goes beyond the emphasis on knowledge because it also emphasizes the importance of developing an overall repertoire of understanding, motivation, and skills that enable one to move in and out of lots of different cultural contexts. Cultural, sociological, and individual dynamics occurs for each personality in cross-cultural settings $[3 ; 4 ; 22]$.

The purpose of the research is to understand the strategic approaches which should be taken into account in teaching cross-cultural interaction of translators. These include developing understanding and acceptance of nonnative cultures, increasing the availability to interact with them.

\section{Meta-principle of cross-cultural availability formation}

As Bibler points out that the task of education is to prepare «a man of culture» who can work with the knowledge, different types of thinking and recognizes the ideals of different cultures [7, p. 29].

That is why educational process has to reflect new educational goals: to prepare students for a life in cultural diversity, form availability to interact in global context, learn to appreciate not only their own national culture, but also to understand the uniqueness of other cultures and respect them.

Dialogue based on the equality of cultures helps to save cultural diversity through mutual acceptance and sharing values. Dialogic interaction means exchange of meanings that allow people to interact with others as «personalities - cultures» and create themselves during this interaction.

The mechanism of mutual influence is a dialogue interpreted as a form of individuals' communication, the way to interact with the objects of culture and art in historical perspective.

Thus, dialogue implies qualitative differences of persons who enter into it. It's a kind of a «breakthrough» that represents relationships of qualitatively different «integrities» whose interaction generates dialogue as a phenomenon of human culture.

We understand a dialogue as an interpersonal process where qualitatively different intellectual and value positions meet. It involves two «logics» focused on the one objectivity. During this process people clarify and identify cultural values of each other. This position does not mean the fact of renunciation of their own beliefs, values but provides the benefit 
principle of equality of the parties in regard to the interpretation of the facts and their estimation.

Therefore we have to take into account essential features of any dialogue: uniqueness of its participants and their fundamental equality; difference and variation of dialogue participants' points of view; the orientation a person on the perception and active interpretation of another point of view; participants' mutual correlation and additional position in the dialogue; personal orientation of objectives and content of a dialogue; prediction of partner's response in utterances and acts; improvised character of a dialogue that involves free expression of person's activity in generating new information; meeting of existing ideas, points of view and producing fundamentally new spiritual sense in the process of creative synthesis.

It's obvious that the formation of translators' cross-cultural availability to interact across cultures is possible only through their involvement in the dialogue of cultures (direct or indirect) in the educational process of a university. Teaching students cross-cultural interaction becomes a mechanism of their behavior's correction and correlating it with regulatory standards, ideals and values of other cultures. However, students not only acquire knowledge about the world, other cultures and their carriers, but also form some personal ideas about their place and purpose in the world. Thus there is awareness, comprehension, understanding and acceptance of the dialogue values at the level of personal meaning, ie, formation of value consciousness of the individual.

So there is a valuable dialogue. Participants of interaction enter into dialogue, not because they seek to get something from another. Dialogue is a world of penetration of another personality, and through this person to «Self». «Dialogue of Cultures» as understanding involves not score (better or worse), but the definition of uniqueness of each culture by productive comparison. It appears universal sense of a national culture and its peculiarities. As a result, value experience of cross-cultural interaction participants expands during exploring another culture.

Investigating other cultures must be based on a solid basis of understanding and acceptance of participants' native cultures. Only based on this foundation, we are able to take the next step - to experience the «Other» as our own. The effect of identification, which occurs during the comparison of the native culture with the foreign one, can have two options: 
1) Students see in unknown culture something familiar but presented in another national image. This option requires careful commenting on the facts and realities of other cultures. 2) Exploring cultures students consider them unusual for their cultural beliefs, morals, and other aesthetic tastes and preferences, they find out different meaning of universal values, world view. This option needs special techniques to switch young people into introduced culture.

However, as Bekh noted, one should be careful of primitive understanding of dialogue as situations that occur in language which do not have essential attitude to the idea of dialogue within the concept of culture. Dialogue, a symbiosis of interaction, mutual and self understanding (internal dialogue), can be defined as «phenomenon of human existence» [5].

The result of genuine dialogue, according to Bekh, is cross-cultural tolerance. The scientist offers two strategies of cross-cultural dialogue on the basis of intellectual and emotional unity.

1. Empirically-adaptive cross-cultural strategy or traditional approach. It includes: cross-cultural adaptation; mutual exchange of knowledge; spontaneous interplay; comparative analysis of different cultures. The result of this stage is the formation of mainly motivational individual positions on other cultures.

2. Accumulative and value cross-cultural strategy or developmental approach, which is reflected in the following principles: sensitivity to other cultures; development of cross-cultural capacity; understanding of crosscultural event as creativity; assimilation of cultural values as open system issues that involve personality's understanding the genesis and formation of cultural value sets. The result of this strategy is the formation of active tolerant individual positions on other cultures and desire of its manifestation [5, p. 18-21].

Thus, we can distinguish features of cross-cultural dialogue. Logicperceptional feature means adopting a certain way of thinking (cognitive, technological, artistic, spiritual and moral). Retrieval-stimulating one focuses on innovative solutions to urgent problems (clash of ideas, approaches, and ways of action).

Conceptual approach of our research considers types of dialogue: «vertical» and «horizontal» dialogue of cultures. "Vertical dialogue» is a dialogue that takes place at historical verticals with native culture and plays a crucial role in cultural identification. This is the process of generic 
abilities' appropriation. The peculiarity of the educational process caused by national values is to attract students to the values of native culture. From the start educational activity is based on the national ideal, and then it is transformed into activities to achieve «universal ideal».

Students take an active role understanding culture as «a system of open issuers», tracing the genesis of certain cultural constructs as the values of definite cultures. They become to some extent the creators of these values gaining the «image of men» in the space of world culture. This interaction is parity when mutual changes occur.

Dialogic meeting of cross-cultural interaction participants, immersed in the infinite cultural context, requires its active understanding that involves perception, recognition and interpretation of values in a particular culture. Adequate understanding of cultural context leads students to realization of their personal existence in a culture.

\section{Contextual approach}

Cultural contexts are the means of cross-cultural interaction which represent the model and content of the dialogue, disclose the mechanism of individual's development at the intersection of cultures.

The concept of cultural context brings clarity to understanding of implementation of cross-cultural interaction «mechanism», allows us to determine the essence of the impact of cross-cultural interaction experiences on the process and results of gaining new cultural experience.

Vetbitskyi finds that context is a system of internal and external factors, conditions and behavior of human activity affecting the peculiarities of perception, understanding and transformation of a particular situation. This system determines the meaning and significance of the situation as a whole and refers to «internal» and «external context» [28, p. 44].

Internal context is a system of unique to every human physiological and personality characteristics, conditions, guidelines, attitudes, knowledge and experience; external context is a system of subject, socio-cultural, spatial and temporal characteristics of situations of action. Internal and external contexts in their interaction function as creating content performers at all levels of mental reflection [28, p. 43].

Thus, the internal (personal) context is seen as an image of the world built in interaction under the influence of different cultures (human, ethnic, 
national, etc.) and determines the individual values and sense perception, understanding and transformation of a particular situation of interaction as a whole and its components.

Interpretation of socio-cultural contexts is carried out by immersing them in an individual context. The action of the internal context mechanism, aiming at developing world view, determines the meaning, sense of perception and understanding of the world.

Zhukova considers the basis of this mechanism in the unity of the two processes of thinking: reflection and anticipation [28]. These processes create the system of conditions for the relationship between the external (sociocultural) context and the individual's personality development. Thus, the internal context we think as an effective mechanism of individual human culture development.

According to the definition of the external context of Verbytskiy, we conclude that the external socio-cultural context, stated by ideas of universal values, national, ethnic cultures, is crucial external condition that affects the formation of internal relationships between variables of individual consciousness of a person.

Considering the context as a model of cultural dialogue that unfolds vertically with native culture and horizontally with a variety of world cultures, we define «vertical» and «horizontal» dialogical context as countervailing meeting of cross-cultural interaction participants in the space of cultural context.

We understand the personal culture of intellectual, moral and ethical (spiritual) patterns of behavior and activity, which are constantly in a state of development, changing. People get them in the context of different cultures and follow them in life activity.

In this regard, we believe that the mechanism of counter influence of personality's internal and external contexts of the individual socio-cultural context runs in the space of cross-cultural context.

Respectively, changes in personal culture of individual, held indirectly through cross-cultural context, represent meeting, intersection and interpenetration of different cultural values.

Cross-cultural interaction space (the context) has sense creating influence on the content and process of appropriation of new cultural models by personality and mediates the formation of personal culture. 
Preconditions for reflection and formation attitudes of individual, causing a manifestation of human behavior and actions at the level of personal culture, are formed within the cross-cultural context.

We believe that personal culture of individual, due to the influence of cross-cultural, can be found at such levels that follow each other: the level of cultural sensitivity, the level of cross-cultural competence, the level of subjectivity in the dialogue of cultures.

Consequently, cross-cultural context is integrated multi-level integrity, penetration in a culture, the cultural space where individual unique image of the world of personality (internal personal context) is superimposed on the external context and creates a personal meaning of perception.

Overlay of generated in previous experience individual senses and perception new meanings from outside (their intersection, conflict, interpenetration) is necessary condition for uniqueness of human development.

\section{Axiological approach}

The external context, as we have established, sets its system of values, ideas, rules of behavior. Sense of particular culture is realized in requirements, expectations, moral principles that people learn and follow them in their lives and activities.

Therefore, for the purpose of our research it is necessary to identify and emphasize subjective position of an individual in exploring cultural values in cross-cultural interaction. The following issues are important: 1) individual understanding the way how cultures display their values; 2) transformation of individual value orientations in the process of crosscultural interaction.

1) Individual understanding the way how cultures display their values. Every individual is the bearer of a system of national values. Complexity of his/her position in the space of crossing cultures is determined by the needs to adopt their behavior to another culture for effective interaction. Even spiritual values generally have different significance for different people. Simultaneous existence of different cultural values' projections in the mind of an individual creates difficulties in his/her choosing the way of interpreting them.

Researchers of values solve this problem on the ground of values similarity. They notice the similarity comparing identity of values' structure 
in relations between values within each culture using the most common form of comparison (attitude to nature, time, space, activity, communication, personal freedom and autonomy of the individual, competition, government, human nature) or they use a significant substantive aspect. According to Shvarts, this is a type of motivation in which values appear. He grouped values in units which have a common goal [22].

Investigating cultural values as concerted abstract ideas about what is a good, proper and desirable in a certain culture, the researches aimed to find out in cross-cultural differences and similarities basic value dimensions by which cultures can be compared. They suggested that the value dimensions reflect the major problems which any society faces organizing human activity. Among them Hofstede named social inequality; the relationship between the individual and the group; gender issues; attitude to uncertainty, including control over the display of aggression and emotions [13].

Understanding and interpreting cultural values according to this approach make the participants of cross-cultural interaction active in practice. They have to trace the genesis of certain cultural constructs as values. They become like creators of these explored values to some extent when finding the way how interpret them and solve a cultural problem.

2) Transformation of individual value orientations in the process of crosscultural interaction. Situations of cross-cultural context are determined by the fact that a person in a certain life situation has to make a choice between the values of different cultures. The process of cross-cultural interaction implementation depends on the abilities of participants to recognize and understand values of other cultures.

As already established, the complexity of the content of cross-cultural context affects the selectivity of the personality of cultural values in the course of interaction, because the choice of values can be either conscious or spontaneous.

Conscious selectivity is a characteristic of participants with welldeveloped positive identity. They can influence and control the process of adopting the values of other cultures. Spontaneous selectivity of cultural values confirms the presence of disharmony in personal culture, existing of instability beliefs; lack the skills to develop their own alternatives in selection of specific traditions. This form is extremely dangerous for the 
participants of interaction, because it can lead to loss of personal identity through insufficient level of availability for interaction across cultures. This can make interaction inefficient and does not allow participants exchange their experiences and achievements productively.

The penetration into another culture is associated with acquisition of certain qualities inherent in this culture. Qualitative changes are associated with the effect of immersion into another culture - socio-cultural transformations of an individual.

According to Bochner, implications for cross-cultural contacts may be as follows: in the process of adaptation a person can reject own culture for the benefit of another one, reject another culture for the benefit of his/her own culture, oscillate between two cultures or synthesize two cultures [8].

Only a person, who is «the mediator between cultures», responds to the influence of other cultures by selecting, combining and synthesizing values inherent in this culture without infringing own cultural characteristics and shows the ability to make connections between different cultural systems. These individuals provide the correct methods of entry forms to respond to new socio-cultural environment, have cross-cultural skills and adequate self-perception.

Thus, the conflict of cultures is valued at the interaction of internal (personal) and external (social and cultural) context. In resolving this conflict, people can choose different strategies-schemes of interaction: scheme of isolation of a new culture for maximum preservation of native culture; scheme of merging with a new culture; scheme of opposition constructing barriers between cultures; scheme transformation combining elements of native culture and new one. Transformation strategy of is quite difficult to achieve because it demands harmony in combination of cultural elements.

The only one thing, that would guarantee the harmonious combination of cultural values, is positive ethnic identity. Positive identity of a person represents a balance of values' tolerance and allows individual to interiorize values of another culture without compromising his/her own. It contribute in better understanding the rules that govern social relations in a new culture and gives flexibility in carrying out definite role in the society in accordance with another cultural norms. 


\section{Facilitation of students' cross-cultural interaction}

Cross-cultural interaction availability is not originally given or inherent characteristic of a person. It is formed in real educational activities of interaction based on the acquisition of students' experience in cross-cultural interaction. This combination of teaching techniques generates relevant guidelines, abilities and skills which are converted (corrected) and fixed in the forms of personal qualities and characteristics of individually marked activity.

Binary nature of cross-cultural interaction provides guidance on interpersonal contacts of its participants while maintaining their own position of and equating it with the position of another culture person. Hence there is obvious dependence of the potential efficiency of an individual in the space of different cultures and the nature of interaction in educational process. Developing integrated personality traits, focused on cross-cultural interaction availability, is based on facilitating of students' interaction [24].

Facilitation is the phenomenon of interpersonal interaction, which increases the productivity of teacher-students interaction through its particular style and a personality of the teacher. This approach is based on existing human tends to grow, to develop, to realize their full potential.

According to the basic concepts of Rogers' theory, facilitation is a belief in the eternal, constructive and creative wisdom of a man; belief in social and the personal nature of means to actualize the potential of constructive personal potential in the process of interpersonal communication» [20].

Given the above, the basic tenets of students' availability formation to interact across cultures based on facilitation approach are determined the following: 1) motivation, needs and interest of students to gain knowledge in the theory of cross-cultural interaction, providing personal sense of cognitive activity; 2) a set of operational skills of a teacher, which are the basis of interactive forms of interpersonal interaction when teaching cross-cultural interaction; experience in collaboration, aimed at mutual expression values and attitudes of all interaction participants; 3) active personal position in terms of self-actualization, self-knowledge and selfdevelopment through reflective practice [25].

Facilitation of cross-cultural interaction in educational process allows analyzing the specific situations of cultural contexts, formulating goals and predicting the results of interaction. 
The experience of interpersonal interaction stimulates activity in establishing interpersonal relationships of trust and tolerance, sensitivity to other cultures and desire for cooperation.

Consequently, the organization of cross-cultural interaction in educational process is a complex system of interpersonal relations that arise between its participants - students and teachers, who determine development of each.

\section{Practical approach to cross-cultural competence formation}

Teaching a foreign language is not enough in today`s global world. Acquiring foreign language skills cannot be separated from developing cross-cultural competence. There are a number of reasons for this. The globalization of national economies has increased the need for cross-cultural communication. Future specialists have to deal with culturally diverse staff, suppliers and customers. Since culture affects every facet of our life - from dress code to the way of doing business - people need to develop particular attitudes and skills to become successful in their home country as well as abroad. The acquired skills will allow them to interact in an appropriate way when working with people who have different cultural backgrounds.

Defining cross-cultural competence is a complex task. At the heart of cross-cultural competence is the preparation of individuals to interact appropriately and effectively in different cultural contexts. As a result, understanding of culture becomes an integral component of intercultural competence [17, p. 48].

Well organized training can help to understand cultural differences: decision making, communication and management style, leadership and meetings. John Some of the most common misconceptions reflect the way in which different cultures understand time, thought patterns and reasoning, personal space, material possessions, language, religion, ethnocentric beliefs as well as the presence of many languages» [21, p. 34].

Cross-cultural competence is the ability to communicate successfully at all levels of professional activity. This competence can be obtained as an essential component of the English language teaching process at universities. The use of English as a tool for cross-cultural communication plays an important role in acquiring knowledge. Effective ways of acquiring cross-cultural competence are solving practical problems, dealing with case studies and using authentic materials. 
Byram depicts a person who gains skills in cross-cultural communicative competence as an individual who is successful in: building relationships while speaking the foreign language of the other participant; negotiating how to effectively communicate so that both individuals' communicative needs are addressed; mediating conversations between those of diverse cultural backgrounds; and continuing to acquire communicative skills in foreign languages not yet studied [9].

In Byram's Model of Intercultural Communicative Competence, foreign language teachers are asked to guide learners through the process of acquiring competencies in attitudes, knowledge, and skills related to cross-cultural competence while using a foreign language. Teachers have to facilitate students offering activities in which attitudes about the «other» are considered. The goal for the students is to start by questioning their preconceived ideas before entering into a process of discovery about the «other» with the intent of becoming more willing to seek out and engage with otherness in order to ultimately experience relationships of reciprocity $[10$, p. 21]. As students continue to engage in analysis of other cultures, certain knowledge must be acquired. It is imperative that the foreign language educator allows time to explore the national identity of the home culture and the target culture in relation to history, geography, and social institutions $[10$, p. 25]. Once learners have taken time to discover the similarities and differences between their culture and that of the target culture, the teacher must craft activities that will prepare students to build relationships with people of diverse backgrounds and languages [10, p. 27]. Next, foreign language students must be provided the time and the space to develop skills in interpreting of cultural context. When students begin to identify ethnocentric perspectives and misunderstandings related to cross-cultural situations, they manage to understand and explain the origins of conflict and mediate situations appropriately in order to avoid misinterpretations $[10$, p. 28]. Finally, skills in discovery and interaction allow intercultural speakers to identify similarities and differences between home cultures and foreign cultures resulting in successful communication and the establishment of meaningful relationships [10, p. 31]. A successful cross-cultural speaker seeks out opportunities to meet individuals from diverse cultures in order to share information through communication in a foreign language. 
Based on the information provided in Byram's Model of Intercultural Communicative Competence [10], foreign language teachers have to reconsider methods for teaching language and culture in the classroom.

The focus shifts from preparing students to communicate without error in order to survive a foreign culture to communicating openly in order to build relationships so that they can thrive in a foreign culture. When the teaching of intercultural communicative competence includes models of reciprocal relationships in which students play the role of a «social actor», students experience the mutual discovery of another language and culture, and language classrooms become places where students and teachers consider questions of values and morals, which can ultimately promote the notion of democracy.

Nowadays the state of the teaching methods of foreign languages in universities does not always reflect the real needs of the society in the development of foreign languages. English for Communication programs include only general guidelines for forming linguistic and communicative competences for students of higher educational institutions. Unlike the required minimum of school education, programs at the university do not indicate the specific degrees and methods of differentiating language skills. Therefore, the choice of educational material remains for the teacher.

On the basis of the analysis of some educational and methodological complexes for the study of a foreign language, one can conclude that, at the initial stage of study at a faculty of foreign philology, the acquisition of a foreign language can be achieved by including in the teaching materials operational-semantic differences, which are correlated both in the native language and in the language being studied. This aspect of mastering foreign language in an intensive course corresponds to the section "Vocabulary oriented learning». It contains only lexical material, which provides the process of communication in its various aspects. Student engagement is the base of authentic dialogues and techniques for working with them with the purpose of gaining cross-cultural communicative competence. All study guides are universal in nature, have no narrow thematic constraints and can be used in work on a variety of subjects.

The cross-cultural orientation in teaching English for Communication may be added to the dominant cultural and household topics. In this case it becomes possible to conduct regular conversations about events from 
students' lives. Naturally, that the intercultural content of each topic or sub-topic requires appropriate lexical content. So, when studying the topic «customs and traditions» it is possible to provide students the opportunity to compare cultural differences of countries using nationally biased lexical units of native and target languages. When selecting vocabulary, the principle of functionality should not conflict with the principle of frequency, although in some cases it is inevitable. However, the selected vocabulary for each individual topic cannot, of course, be introduced simultaneously, all at once. It should be done in small, strictly dosed portions. Such approach depends on specific nature of cultural and household topics. As it was discovered through a special survey, within these themes, the flow of new, communicatively-motivated information is continuously carried out, in connection with which there is a possibility of repeated return to each of them and the expansion of these themes to the new ones, introducing new portions of intercultural vocabulary. This is the main specificity of cultural and household themes, from which we can draw the following conclusion: the main cultural themes should be repeated from year to year with their gradual expansion and complication of intercultural lexical units. They should be studied in the form of expanding intercultural semantic concepts, each of which marks a return to the previous studied topic or in the next academic year and is associated every time with the introduction of the next portion of communicative and valuable vocabulary.

The possession of the linguistic material is necessary for the implementation of intercultural communication and can be achieved only with the complex study of all kinds of linguistic activity and the assimilation of the linguistic material in the interaction of all analyzers, that is, in the unity of speaking, listening, reading and writing.

The process of translators of cross-cultural communication in Ukrainian universities can be based on the analysis and interpretation of real cultural contacts. Therefore, the most effective method of teaching intercultural communication is training. Traditional forms of learning suggest predominantly general development of the individual, while the training is more focused on practical requirements and the study of specific situations. This orientation stimulates the development of a whole group of applied methods, the use of which in the learning process made it possible to make learning cross-cultural communication effective and purposeful. 
Here are some examples of the following methods:

1. The method of interactive modeling is aimed at conscious reproduction of various individual and group situations of cross-cultural communication. Due to this method cross-cultural and emotional energy of the participants of the educational process is directed to the analysis and assessment of situations. Simplified world of interactive models enables participants to understand and explore the ways and types of relationships in crosscultural contacts better than in real life. We can offer a discussion of the problem situation aroused in the process of communication between representatives of different cultures, which differ in language, behavior, customs, etc [26, p. 35].

2. The method of stimulation is to create artificially a specific situation of intercultural communication and to predict possible options and outcomes, based on different points of view and aspects. Situations allow students to enter the image of a person of another culture. An important feature of this method is the compulsory creation of conditions for cultural creativity, since creativity itself is the main activity of its participants. Implementation of these requirements to a large extent is ensured by the use of simulation games. The goal of simulation games is to teach students how to function in a culture that means being in an unfamiliar cultural environment, which feelings and emotions can be felt by people at the same time. Participants have the opportunity to test themselves in different roles. Game results are discussed [27, p. 49].

3. The method of problem situations is to organize such situations, in which intellectual-ethical issues transform into emotional. Due to this, the participants understand the lack of resources used; find in cooperation with the teacher the necessary material to overcome the difficulties, independently set the tasks for the development of their own capabilities, which are necessary for the development of an appropriate strategy of action in the indirect or immediate situation of cross-cultural communication [27, p. 50].

In process of education teachers and student become moderators of cross-cultural training performance. It is important to underscore some points: 1) representation of the cross-cultural interaction model by educators; 2) interdependence of learning style and teaching modes in training performance; 3 ) egalitarian teacher-student relations in teaching performance.

Learning how to instruct the students in the art of cross-cultural interaction is a necessary objective for the effective educators. The teachers should take the lead and develop the strategies to provide that their students 
will learn the cross-cultural interaction skills. It is extremely important for the educators to elicit academic performance from the students. It is the educator's responsibility to ensure the students' support of cross-cultural awareness, sensitivity and communication competence.

Learning style depends on how information was processed and perceived. The educator's teaching method and the students' learning style can moderate the relationship between the perceived need for student training and teaching effectiveness. This conceptual framework was developed based on a thorough review of the relevant literature and an integration of previous study results.

The participatory model can be characterized as a «subjectivistic» interactive approach. The educators and universities that practice this approach believe that the knowledge should be created through interaction rather than being just reproduced. Thereby the knowledge is socially reconstructed on the basis of the teachers/students' past experiences.

This process-orientated paradigm emphasizes the participation and interaction of all various stakeholders. The participatory-based educational process makes learners realize the important role they play in formulating their own curriculum to make it compatible and modified. It stimulates them to take an active part in education process turning it into an interactive form. The basis of the participatory model is to consider the learning-teaching process as the way of exchanging the ideas to form new knowledge.

The use of this approach in cross-cultural education (training) can create an atmosphere of cooperation in which the students can get an opportunity for effective learning by exposing their creative skills, expressing their opinions freely, and exchanging their ideas with each other as well as with their teachers. Consequently, they avoid their learning-related fear and become more confident by getting a chance to show their creative power.

\section{Conclusion}

Conceptual approaches, presented in this article, we consider as methodological tool aimed at providing a fundamental and holistic understanding of personality development in cross-cultural interaction, foundations and mechanisms of its implementation.

Dialogic approach becomes a mechanism of self-identity, the way of understanding the perception of the world in a paradigm of «I - Another». 
In this respect, dialogue is seen as a space of interpersonal interaction, based on equality of partners. This understanding of cross-cultural interaction captures the interaction of educational process participants on the sociocultural, interpersonal and intra personal levels. Dialogue interaction is a mean of adjusting the behavior of student, correlating it with regulatory standards, ideals and values of other cultures. Students not only acquire knowledge about the world, other cultures but also form some personal ideas of their own place in this world. Comprehension, understanding and acceptance of cultural values in a dialogue take place at the level of personal meaning.

Contextual approach involves consideration of cross-cultural context as a model of dialogue and mechanism for personal development in cross-cultural interaction, which provoke changes in internal (personal) context and lead to new manifestations of personal culture to the level of cultural sensitivity, cross-cultural competence and subjectivity in the dialogue of cultures.

Axiological approach gives the ground for orientation of the individual in understanding the way how other cultures display their values. It explains socio-cultural transformations that person inevitably suffers in the process of cross-cultural interaction and that should be taken into account during personality development in cross-cultural interaction.

It has been determined that a translator («cultural mediator») is not inherent characteristic, but it is acquired in the real world of interaction and in activities in educational process of high school. It was revealed the dependence of personal efficiency in different cultures from the character and forms of interaction of educational process' participants that should promote individual development in cross-cultural context.

Effective communication in translation requires more than mastering grammar and vocabulary of a language. It is the process that requires also knowledge of culture. Culture becomes an important part of the language teaching process. Having knowledge in cross-cultural competence for translator is the key to successful professional activity.

The three factors specify the effective teacher-student interaction as a moderator of cross-cultural training performance. The cognitive (gnosiological) factor: knowledge of dialogue forms of interaction, and educators' cultural proficiency. The emotive-value (axiological) factor: drive to dialogue interaction, openness, and self-efficacy. The behavioral (praxeological) factor: involvement, participatory, and collaboration. 


\section{References:}

1. Adler P.S. (1998) Beyond Cultural Identity: Reflections on Multiculturalism. In Basic concepts of intercultural communication. Selected Readings. Boston, London: Intercultural Press, pp. 225-246.

2. Ang S., Van Dyne L., \& Rockstuhl T. (2015) Cultural intelligence: Origins, conceptualization, evolution, and methodological diversity. In M.J. Gelfand C.Y. Chiu \& Y.Y Hong (Eds.), Handbook of advances in culture and psychology, 5: 273-323. New York: Oxford University Press.

3. Arasaratnam L.A., Doerfel M.L. (2005) Intercultural communication competence: Identifying key components from multicultural perspectives. International Journal of Intercultural Relations, no. 29, pp. 137-163.

4. Barnlund D. (1998) Communication in Global Village. In Basic Concepts of Intercultural Communication. Selected readings. Boston. London: Intercultural Press.

5. Bekh I. (2008) Multicultural interaction as the aim of personality's development. Kyiv: Press Ukraine.

6. Bennett J.M. \& Bennett M.J. (2004). Developing intercultural sensitivity: An integrative approach to global and domestic diversity. In D. Landis, J. M. Bennett, \& M. J. Bennett (Eds.) Handbook of intercultural training (3rd ed., pp. 147-165). Thousand Oaks, CA: Sage.

7. Bibler V. (1989) Culture. Dialog of cultures. Philosophy issues, no. 6, pp. 31-43.

8. Bochner S. (1982) The social psychology of cross-cultural relations. In Cultures in contact (ed. by S. Bochner). Oxford: Pergamon Press.

9. Byram M. (1997) Teaching and Assessing Intercultural Communicative Competence. Clevedon, UK: Multilingual Matters.

10. Byram M., Gribkova B. \& Starkey H. (2002) Developing the Intercultural Dimension in Language Teaching: A Practical Introduction for Teachers. Strasbourg: Council of Europe.

11. Fischer K. (2011) Colleges adapt to new kinds of students from abroad, Chronicle of Higher Education, vol. 57, no. 38, pp. 1-14.

12. Gudykunst W. (1997) Communication with strangers: An approach to intercultural communication. Boston: McGraw Hill.

13. Hofstede G.J. (1997) Cultures and Organizations: Software of the Mind. New York: McGraw-Hill USA.

14. Hofstede G. (1984) Culture's Consequences: International Differences in Work-Related Values. Beverly Hills, CA: Sage.

15. Johnson T.P., Shavitt S., Holbrook A.L. (2011). Survey response styles across cultures. In Matsumoto D., van de Vijver F. J. R. (Eds.). Cross-cultural research methods in psychology (pp. 130-178). Cambridge, UK: Cambridge University Press.

16. Matsumoto D. (2001) The Handbook of Culture and Psychology. New York: Oxford University Press.

17. Nieto S. (1999) The Light in Their Eyes: Creating Multicultural Learning Communities. Multicultural Education Series. New York, NY: Teachers College Press. 
18. Osborne D. (2012) Factors in international student identity formation: processes and challenges. Sino-US English Teaching, vol. 9, no. 4, pp. 1035-1044.

19. Rich A.L. (1971) A Model of Intercultural and Interracial Communication. Washington, D.C.: Distributed by ERIC Clearinghouse.

20. Rogers C.R. (1961) On Becoming a Person. Boston: Houghton Mifflin.

21. Saee J. (2007) Intercultural awareness and intercultural success. EFMD Global Focus, vol. 01, issue 03, pp. 56-57.

22. Schwartz S. H. (2004) Basic human values: Their content and structure across countries. Brasilia: Editora Universidade de Brasilia.

23. Schwartz S. H., Cieciuch J., Vecchione M., Davidov E., Fischer R., Beierlein C., Ramos A., Verkasalo M., Lönnqvist J.-E., Demirutku K., Dirilen-Gumus O., \& Konty M. (2012). Refining the theory of basic individual values. Journal of Personality and Social Psychology, no. 103, pp. 663-688.

24. Solodka A. (2013) Personality Characteristics as Predictors of Affective Availability to Interact across Cultures. Arab World English Journal, vol. 4, no. 2, pp. 213-219.

25. Solodka A. (2013) Theoretical backgrounds of cultural assimilator and its usage in cross-cultural education. European Applied Sciences, no. 4, pp. 88-91.

26. Solodka A. (2013) Development of cross-cultural training. Science and Education: a new Dimension. Pedagogy and psychology, vol. 3, pp. 31-37.

27. Solodka A. (2014) Formation the availability of pedagogical process participants to interact across cultures: model and methodic. British Journal of Science, Education and Culture, no. 5, pp. 46-52.

28. Verbitskyi A. (1999) New educational paradigm and context education. Moscow: INPRESS.

29. Zhukova N. (2005) Contexts in education: monograph. Moscow: INPRESS. 